\title{
Thermodynamic Calculation of Phase Equilibria in As-Fe-In Ternary System Based on CALPHAD Approach
}

\author{
Munekazu Ohno ${ }^{1}$ and Kanji Yoh $^{2}$ \\ ${ }^{1}$ Division of Materials Science and Engineering, Graduate School of Engineering, Hokkaido University, \\ Sapporo 060-8628, Japan \\ ${ }^{2}$ Research Center for Integrated Quantum Electronics, Hokkaido University, Sapporo 060-8628, Japan
}

\begin{abstract}
Thermodynamic calculation of phase equilibria in As-Fe-In ternary system is performed based on Calphad approach, directing a special attention to fabrication process of Fe/InAs hybrid structure for spin injection device. For this, the thermodynamic assessment of Fe-In binary system is first carried out utilizing reported experimental data. Then, the liquidus surface of the ternary system and invariant reactions are calculated. The isothermal sections in low temperature region are presented and discussed in the light of the optimization of the growth temperature of Fe film on InAs substrate during the fabrication process. [doi: $10.2320 /$ matertrans.MER2008437]
\end{abstract}

(Received December 1, 2008; Accepted February 19, 2009; Published April 8, 2009)

Keywords: CALPHAD, spin injection device, Fe/InAs hybrid structure, phase equilibria

\section{Introduction}

Spin injection from ferromagnetic metal into semiconductor is one of the key issues in emerging field of spintronics. ${ }^{1-3)}$ $\mathrm{Fe} /$ InAs hybrid structure has attracted attention as a candidate for realizing high spin injection efficiency. ${ }^{4-7)}$ The spin injection efficiency is critically dependent on the interface quality of the hybrid structure. Considerable efforts have been devoted to optimize the process parameters during Molecular Beam Epitaxy (MBE) growth of Fe film on the semiconductors. ${ }^{4-7)}$ In early studies on the Fe growth on GaAs substrate, the growth temperature between 420 and $450 \mathrm{~K}$ was chosen so that the Fe film can grow on the GaAs without forming defects of high density. However, it was reported that the epitaxial growth of Fe film on the InAs substrate at $450 \mathrm{~K}$ involves an interface reaction, resulting in the formation of a compound at the interface and, consequently, low spin injection efficiency was observed. ${ }^{7)}$ There have not been any conclusive data identifying the type of the reaction at the interface. On the other hand, the MBE growth of Fe film on the InAs at $296 \mathrm{~K}$ leads to a clear interface, i.e., the interface without the formation of compound and high spin injection efficiency of 30-40\% was realized. ${ }^{7)}$ It should be noted that the optimization of the fabrication process parameters of the hybrid structure has been currently attempted by a trial and error.

The information on the phase equilibria is fundamental in the development of electronic devices. ${ }^{8-11)}$ Especially, the isothermal section for metal/III-V semiconductor in low temperature region is of great importance in understanding and predicting the interface reaction during the fabrication process, as discussed in detail for metal/GaAs system. ${ }^{9)}$ The isothermal section for As-Fe-In ternary system at $300 \mathrm{~K}$ has been estimated from the formation enthalpy of the compounds based on the Miedema's model. ${ }^{12)}$ In order to obtain the further information about the phase equilibria associated with $\mathrm{Fe} / \mathrm{InAs}$ hybrid structure, in this work, the isothermal sections at higher temperature are clarified based on the Calphad approach. ${ }^{13)}$ The Calphad is an empirical approach in which the thermodynamic quantities of the system are described through simple phenomenological expressions for the Gibbs energies of all the phases. The Calphad method based on well-established thermodynamic parameters enables a precise description of the phase equilibria of multicomponent system. To this end, we performed the thermodynamic modeling for the As-Fe binary system based on the first-principles total energy calculations for the As-Fe compounds. ${ }^{14)}$ The thermodynamic modeling of the As-In system was reported in the early work, ${ }^{15}$ ) while the Fe-In system has not been subjected to the thermodynamic assessment. In this study, therefore, we first carry out the thermodynamic modeling for the Fe-In binary system and then perform the calculation for the ternary system, demonstrating the isothermal sections associated with the fabrication process of $\mathrm{Fe} / \mathrm{InAs}$ hybrid structure.

\section{Calphad Approach}

In this section, we present the thermodynamic modeling for the As-Fe-In ternary system. For precise description of phase equilibria of the ternary system, it is indispensable to develop the thermodynamic descriptions of the binary edge systems with a high accuracy based on well-established experimental data. As already mentioned, the binary As-In and As-Fe systems have been subjected to the detailed thermodynamic assessments. ${ }^{14,15)}$ In this study, we perform the modeling for the Fe-In binary system.

\subsection{Fe-In binary system}

The phase equilibria of the Fe-In binary system have been reviewed. ${ }^{16)}$ The phase equilibria of this system are characterized by existence of a miscibility gap in the liquid, monotectic reaction $\mathrm{L}_{1} \leftrightarrow(\delta \mathrm{Fe})+\mathrm{L}_{2}$, catatectic reaction $(\delta \mathrm{Fe}) \leftrightarrow(\gamma \mathrm{Fe})+\mathrm{L}_{2}$, peritectic reaction $(\gamma \mathrm{Fe})+\mathrm{L}_{2} \leftrightarrow(\alpha \mathrm{Fe})$ and eutectic reaction $\mathrm{L}_{2} \leftrightarrow(\alpha \mathrm{Fe})+(\mathrm{In})$. The monotectic temperature was measured in the early experimental works. ${ }^{17-19)}$ The solubility of $\mathrm{Fe}$ in the In-rich liquid phase was reported $^{17,20)}$ and the solubilities of In in $(\delta \mathrm{Fe}),(\gamma \mathrm{Fe})$ and $(\alpha \mathrm{Fe})$ were also determined. ${ }^{17,19)} \mathrm{We}$ employed these experimental data in the present assessment. 
The molar Gibbs energy for solution phases such as liquid, $(\alpha \mathrm{Fe})$ and $(\gamma \mathrm{Fe})$ is expressed by the following equation,

$$
\begin{aligned}
G^{\phi}= & x_{\mathrm{Fe}} G_{\mathrm{Fe}}^{0, \phi}+x_{\mathrm{In}} G_{\mathrm{In}}^{0, \phi}+R T\left(x_{\mathrm{Fe}} \ln x_{\mathrm{Fe}}+x_{\mathrm{In}} \ln x_{\mathrm{In}}\right) \\
& +x_{\mathrm{Fe}} x_{\mathrm{In}} \sum_{v=0} L_{\mathrm{Fe}, \mathrm{In}}^{\phi, v}\left(x_{\mathrm{Fe}}-x_{\mathrm{In}}\right)^{v},
\end{aligned}
$$

where $R$ is the gas constant, $x_{i}$ with $i=\mathrm{Fe}$ and In is the molar fraction of Fe and In, respectively. $G_{i}^{0, \phi}$ is the Gibbs energy function for pure element $i$ in phase $\phi$, which was taken from the SGTE compilation by Dinsdale ${ }^{21)}$ and $L_{\mathrm{Fe}, \mathrm{In}}^{\phi, \nu}$ is the $v^{\text {th }}$ Redlich-Kister parameter. The magnetic energy contribution is taken into account in the model for $(\alpha \mathrm{Fe})$ and $(\gamma \mathrm{Fe})$ solution phases on the basis of the method developed by Hillert and Jarl. ${ }^{22}$ ) The Gibbs energies thus described are quantified based on the experimental data for the phase boundaries.

\subsection{As-Fe-In ternary system}

The crystal structures of solid phases in this ternary system are summarized in Table 1. No ternary compounds are reported in this system. ${ }^{23)}$ The experimental data available for this ternary system is the one only for the phase equilibria on the section InAs-AsFe by slow directional solidification experiment. $^{24)}$ The thermal signal was detected at $\mathrm{T}=$ $1203 \pm 2 \mathrm{~K}$ which was confirmed to be a reaction $\mathrm{L} \leftrightarrow$ InAs + AsFe by means of the microstructural observation and X-Ray Diffraction (XRD) analysis. Although the InAsAsFe section was supposed to consist of a simple eutectic pseudobinary system with the eutectic reaction, it was pointed out that there possibly exists the huge liquid miscibility gap extending from the binary Fe-In system into ternary. ${ }^{23)}$

For the calculation of the ternary system, we employed the thermodynamic descriptions of As- $\mathrm{In}^{15)}$ and As- $\mathrm{Fe}^{14)}$ binary edge systems in addition to the one for Fe-In system obtained in this study. As described above, there is only the experimental data on InAs-AsFe section available in this
Table 1 Crystal structures of solid phases in As-Fe-In system. The last column represents the sublattices and constituent for the Gibbs energy model. The Gibbs energy for $(\alpha \mathrm{Fe})$ and $(\delta \mathrm{Fe})$ phases are described with the single solution model.

\begin{tabular}{cccccc}
\hline Phase name & $\begin{array}{c}\text { Pearson } \\
\text { symbol }\end{array}$ & $\begin{array}{c}\text { Space } \\
\text { group }\end{array}$ & $\begin{array}{c}\text { Strukturbericht } \\
\text { designation }\end{array}$ & Prototype & $\begin{array}{c}\text { Sublattices and } \\
\text { constituent }\end{array}$ \\
\hline$\alpha \mathrm{As}$ & $h R 2$ & $R \overline{3} m$ & $\mathrm{~A} 7$ & $\alpha \mathrm{As}$ & $(\mathrm{As})$ \\
$(\alpha \mathrm{Fe}) /(\delta \mathrm{Fe})$ & $c I 2$ & $\operatorname{Im} \overline{3} m$ & $\mathrm{~A} 2$ & $\mathrm{~W}$ & $(\mathrm{As}, \mathrm{Fe}, \mathrm{In})$ \\
$(\gamma \mathrm{Fe})$ & $c F 4$ & $F m \overline{3} m$ & $\mathrm{~A} 1$ & $\mathrm{Cu}$ & $(\mathrm{As}, \mathrm{Fe}, \mathrm{In})$ \\
$\mathrm{In}$ & $t \mathrm{I} 2$ & $I 4 / m m m$ & $\mathrm{~A} 6$ & $\mathrm{In}$ & $(\mathrm{In})$ \\
$\mathrm{InAs}$ & $c F 8$ & $F \overline{4} 3 m$ & $\mathrm{~B} 3$ & $\mathrm{ZnS}$ & $(\mathrm{In})(\mathrm{As})$ \\
$\mathrm{As}{ }_{2} \mathrm{Fe}$ & $o P 6$ & $P n n m$ & $\mathrm{C} 18$ & $\mathrm{FeS}$ & $(\mathrm{As})_{2}(\mathrm{Fe})$ \\
$\mathrm{AsFe}_{2}$ & $o P 8$ & $P n m a$ & $\mathrm{~B} 31$ & $\mathrm{MnP}_{2}$ & $(\mathrm{As})(\mathrm{Fe})$ \\
$\left.\mathrm{As}_{2} \mathrm{Fe}\right)_{3}$ & - & - & - & - & $(\mathrm{As}, \mathrm{Va})_{0.75}(\mathrm{Fe})$ \\
$\mathrm{AsFe}_{2}$ & $t P 6$ & $P 4 / n m m$ & $\mathrm{C} 38$ & $\mathrm{Cu}_{2} \mathrm{Sb}$ & $(\mathrm{As})(\mathrm{Fe})_{2}$ \\
\hline
\end{tabular}

ternary system and, therefore, we assume no ternary solubility in the compounds and did not introduce any ternary parameters into the model for solution. The molar Gibbs energy for solution phases in the ternary system is expressed as follows,

$$
\begin{aligned}
G^{\phi}= & x_{\mathrm{As}} G_{\mathrm{As}}^{0, \phi}+x_{\mathrm{Fe}} G_{\mathrm{Fe}}^{0, \phi}+x_{\mathrm{In}} G_{\mathrm{In}}^{0, \phi} \\
& +R T\left(x_{\mathrm{As}} \ln x_{\mathrm{As}}+x_{\mathrm{Fe}} \ln x_{\mathrm{Fe}}+x_{\mathrm{In}} \ln x_{\mathrm{In}}\right) \\
& +x_{\mathrm{As}} x_{\mathrm{Fe}} \sum_{v=0} L_{\mathrm{As}, \mathrm{Fe}}^{\phi, v}\left(x_{\mathrm{As}}-x_{\mathrm{Fe}}\right)^{v} \\
& +x_{\mathrm{Fe}} x_{\mathrm{In}} \sum_{v^{\prime}=0} L_{\mathrm{Fe}, \mathrm{In}}^{\phi, v^{\prime}}\left(x_{\mathrm{Fe}}-x_{\mathrm{In}}\right)^{v^{\prime}} \\
& +x_{\mathrm{As}} x_{\mathrm{In}} \sum_{v^{\prime \prime}=0} L_{\mathrm{As}, \mathrm{In}}^{\phi, v^{\prime \prime}}\left(x_{\mathrm{As}}-x_{\mathrm{In}}\right)^{v^{\prime \prime}}
\end{aligned}
$$

where $x_{\mathrm{As}}$ is the molar fraction of As, $G_{\mathrm{As}}^{0, \phi}$ is the Gibbs energy

\begin{tabular}{|c|c|c|}
\hline Liquid & $\begin{array}{l}L_{\mathrm{As}, \mathrm{Le}}^{\mathrm{L}, 0}=-83810.9+3.0716 T \\
L_{\mathrm{As}, \mathrm{fe}}^{\mathrm{L}, \mathrm{fe}}=75085.7-45.1907 T \\
L_{\mathrm{Fe}, \mathrm{In}}^{\mathrm{L}, 0}=52838.5-5.5432 T \\
L_{\mathrm{As}, \mathrm{In}}^{\mathrm{L}, 0}=-15851-11.2705 T\end{array}$ & $\begin{array}{l}L_{\mathrm{A}, \mathrm{Fe}}^{\mathrm{L}, 1}=50261.1-4.6947 T \\
L_{\mathrm{A}, \mathrm{Se}}^{\mathrm{L}}=-46496.7 \\
L_{\mathrm{Fe}, \mathrm{In}}^{\mathrm{L}, \mathrm{In}}=3999.9 \\
L_{\mathrm{As}, \mathrm{In}}^{\mathrm{L}, 1}=-1219.5\end{array}$ \\
\hline$(\alpha \mathrm{Fe}) /(\delta \mathrm{Fe})$ & 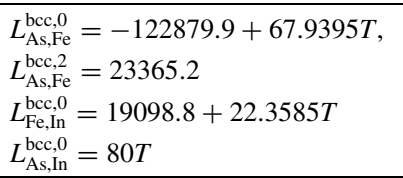 & $L_{\mathrm{As}, \mathrm{Fe}}^{\mathrm{bcc}, 1}=-3248.55+45.8837 T$ \\
\hline$(\gamma \mathrm{Fe})$ & $\begin{array}{l}L_{\mathrm{As}, \mathrm{Fe}}^{\mathrm{fcc}, 0}=-80000+13.5 T \\
L_{\mathrm{Fe}, \mathrm{In}}^{\mathrm{fc}}=23682.9+21.5678 T \\
L_{\mathrm{As}, \mathrm{In}}^{\mathrm{fcc}, 0}=80 T\end{array}$ & \\
\hline InAs & \multicolumn{2}{|c|}{$\begin{array}{l}G^{\mathrm{InAs}}=-73057.2+230.919 T-45.1879 T \ln T-0.00773 T^{2} \\
\quad+69438 T^{-1}+1.41806 \times 10^{-7} T^{3}\end{array}$} \\
\hline $\mathrm{As}_{2} \mathrm{Fe}$ & \multicolumn{2}{|c|}{$G^{\mathrm{As}_{2} \mathrm{Fe}}=-37236.8+10.9657 T+(2 / 3) \cdot G_{\mathrm{As}}^{0, \text { rhombo }}+(1 / 3) \cdot G_{\mathrm{Fe}}^{0, \text { bcc }}$} \\
\hline AsFe & \multicolumn{2}{|c|}{$\begin{array}{l}G^{\mathrm{AsFe}}=-37991.2+122.3339 T-22.1461 T \ln T-4.6066 \times 10^{-3} T^{2} \\
\quad-7.205 \times 10^{-7} T^{3}\end{array}$} \\
\hline $\mathrm{AsFe}_{2}$ & \multicolumn{2}{|c|}{$G^{\mathrm{AsFe}_{2}}=-28919.1+3.9343 T+(1 / 3) \cdot G_{\mathrm{As}}^{0, \text { rhombo }}+(2 / 3) \cdot G_{\mathrm{Fe}}^{0, \text { bcc }}$} \\
\hline $\mathrm{As}_{2} \mathrm{Fe}_{3}$ & \multicolumn{2}{|c|}{$\begin{array}{l}G_{\mathrm{F}: \mathrm{As}}^{0, \mathrm{As}_{2} \mathrm{Fe}_{3}}=-40812.6-5.5208 T+0.75 G_{\mathrm{As}}^{0, \text { rhombo }}+G_{\mathrm{Fe}}^{0, \text { bcc }} \\
G_{\mathrm{Fe}: \mathrm{As}}^{0, \mathrm{As}_{2} \mathrm{Fe}_{3}}=5000-0.3383 T+G_{\mathrm{Fe}}^{0, \text { bcc }}\end{array}$} \\
\hline
\end{tabular}
function for As in phase $\phi$ and $L_{i, j}^{\phi, v}$ is the $v^{\text {th }}$ Redlich-Kister parameter between $i$ and $j$ elements in phase $\phi$. The thermodynamic parameters in this system are summarized in Table 2. It should be pointed out that all the compounds except for $\mathrm{As}_{2} \mathrm{Fe}_{3}$ were modeled as the line compound and

Table 2 Thermodynamic parameters. 
(a)

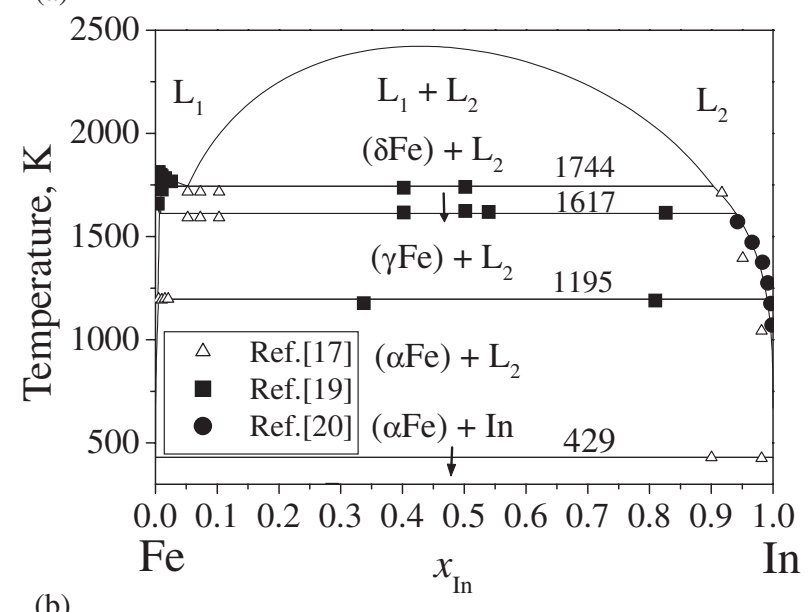

(b)

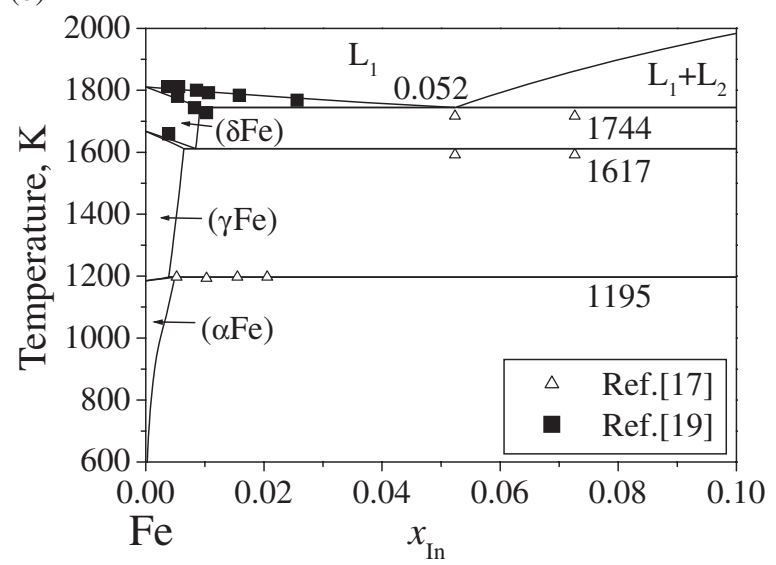

Fig. 1 (a) Calculated phase diagram of Fe-In system. (b) Enlargement of the Fe-rich part.

the Gibbs energies for InAs and AsFe were described with absolute reference state and those for $\mathrm{As}_{2} \mathrm{Fe}$ and $\mathrm{AsFe}_{2}$ were described with floating reference state. The thermodynamic state of $\mathrm{As}_{2} \mathrm{Fe}_{3}$ was modeled by Compound Energy Formalism (CEF). The definition of parameters for these compounds used in Table 2 and the detail of the Gibbs energy models for each phase can be found in the previous reports. ${ }^{14,15)}$

\section{Results and Discussions}

The phase diagram for the binary Fe-In system calculated from the present model is shown in Fig. 1 where the experimental data for the phase boundaries are also indicated. It can be seen that the calculated result is in reasonable agreement with the experimental data, especially those obtained by Dasarathy, ${ }^{19)}$ and Malyugin et al. ${ }^{20)}$ The calculated invariant reactions are summarized in Table 3.

The calculated liquidus surface for the As-Fe-In ternary system is shown in Fig. 2 with the isothermal lines at an interval of $100 \mathrm{~K}$. The liquid composition in the invariant reaction is denoted with a symbol. The reaction type, the temperature and its symbol used in Fig. 2 are summarized in Table 4. The thin dashed line in Fig. 2 represents the isothermal lines for liquid miscibility gap. It is noted that the As-rich part corresponds to the metastable phase diagram, since the stable state of As in these temperature range at
Table 3 Calculated invariant reactions in Fe-In system.

\begin{tabular}{ccccc}
\hline Reaction & Temperature (K) & $\begin{array}{c}\text { Composition of phases involved in } \\
\text { the reaction, } x_{\text {In }}\end{array}$ \\
\hline $\mathrm{L} \leftrightarrow \mathrm{L}_{1}+\mathrm{L}_{2}$ & 2423 & \multicolumn{4}{c}{0.4258} \\
$\mathrm{~L}_{1} \leftrightarrow(\delta \mathrm{Fe})+\mathrm{L}_{2}$ & 1744 & 0.0523 & 0.0092 & 0.903 \\
$(\delta \mathrm{Fe}) \leftrightarrow(\gamma \mathrm{Fe})+\mathrm{L}_{2}$ & 1617 & 0.0085 & 0.0067 & 0.9388 \\
$(\gamma \mathrm{Fe})+\mathrm{L}_{2} \leftrightarrow(\alpha \mathrm{Fe})$ & 1195 & 0.0040 & 0.9904 & 0.0049 \\
$\mathrm{~L}_{2} \leftrightarrow(\alpha \mathrm{Fe})+\mathrm{In}$ & 429 & $\sim 1.0$ & $\sim 0.0$ & $\sim 1.0$ \\
\hline
\end{tabular}

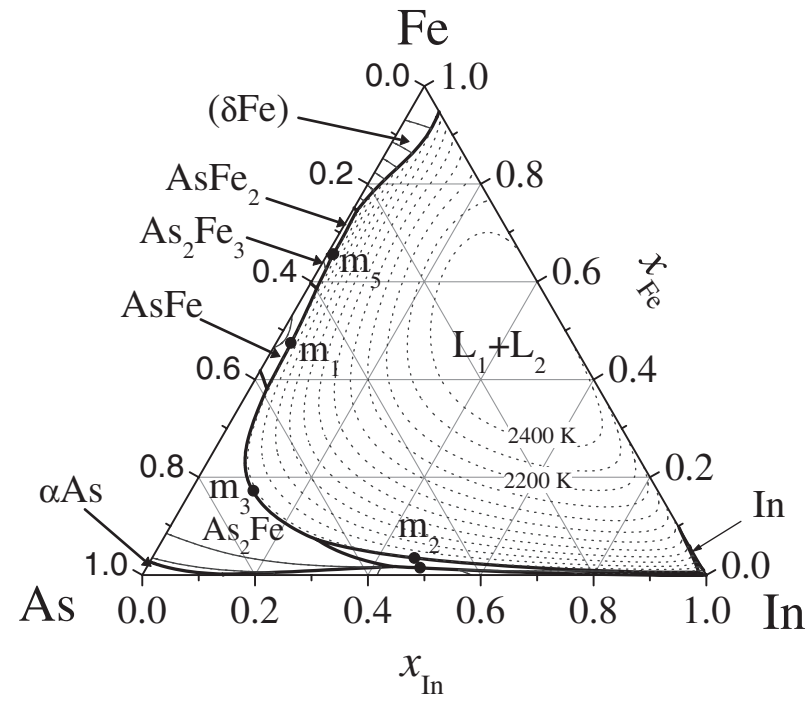

Fig. 2 Calculated liquidus surface. The bold solid lines represent the monovariant lines. The thin solid lines indicate isotherms at an interval of $100 \mathrm{~K}$. The isothermal lines of liquid miscibility gap are also demonstrated by the dashed thin line. The As-rich part corresponds to the metastable phase diagram, since the stable state of As in these temperature range is vapor phase. The phase name in the figure specifies the primary crystallizing phase in the corresponding field.

normal pressures is vapor phase. One can see that the large miscibility gap region extends from the binary Fe-In edge into the ternary as pointed out in the review report. ${ }^{23)}$ The invariant reaction points in the vicinity of the binary edge systems are enlarged in Fig. 3. It is noted that there exist three ternary monotectic reactions in this system and four types of maximum temperatures for degenerated reactions. Especially, the maximum temperatures, $m_{1}, m_{2}$ and $m_{4}$ are located along the section at $x_{\mathrm{As}}=0.5$ between InAs and AsFe compounds. The vertical section between InAs and AsFe compounds is shown in Fig. 4. The experimental data, ${ }^{24)}$ which is only the data available in this ternary system, is also indicated in Fig. 4. The calculated result demonstrates that in this section, the eutectic reaction $\mathrm{L} \leftrightarrow \mathrm{AsFe}+\mathrm{InAs}$ occurs at $1205 \mathrm{~K}$. This is in excellent agreement with the experimental finding ${ }^{24)}$ by means of the thermal analysis, microstructural observation and XRD analysis. It should be pointed out that the present thermodynamic model is based on the interpolation of the thermodynamic models of the binary edges systems without introducing the ternary parameter. Hence, the accuracy of the present calculations cannot be strongly supported. However, all the invariant reactions are located in the vicinity of the binary As-Fe and As-In edges where the ternary parameter is not effective and 
Table 4 Calculated invariant reactions. The reaction type and temperature are shown in 1 st and 2 nd columns, respectively. The 3 rd column indicates a symbol used to indicate the invariant reaction point in Figs. 2 and 3. The liquid compositions at the reaction point are specified in the last two columns.

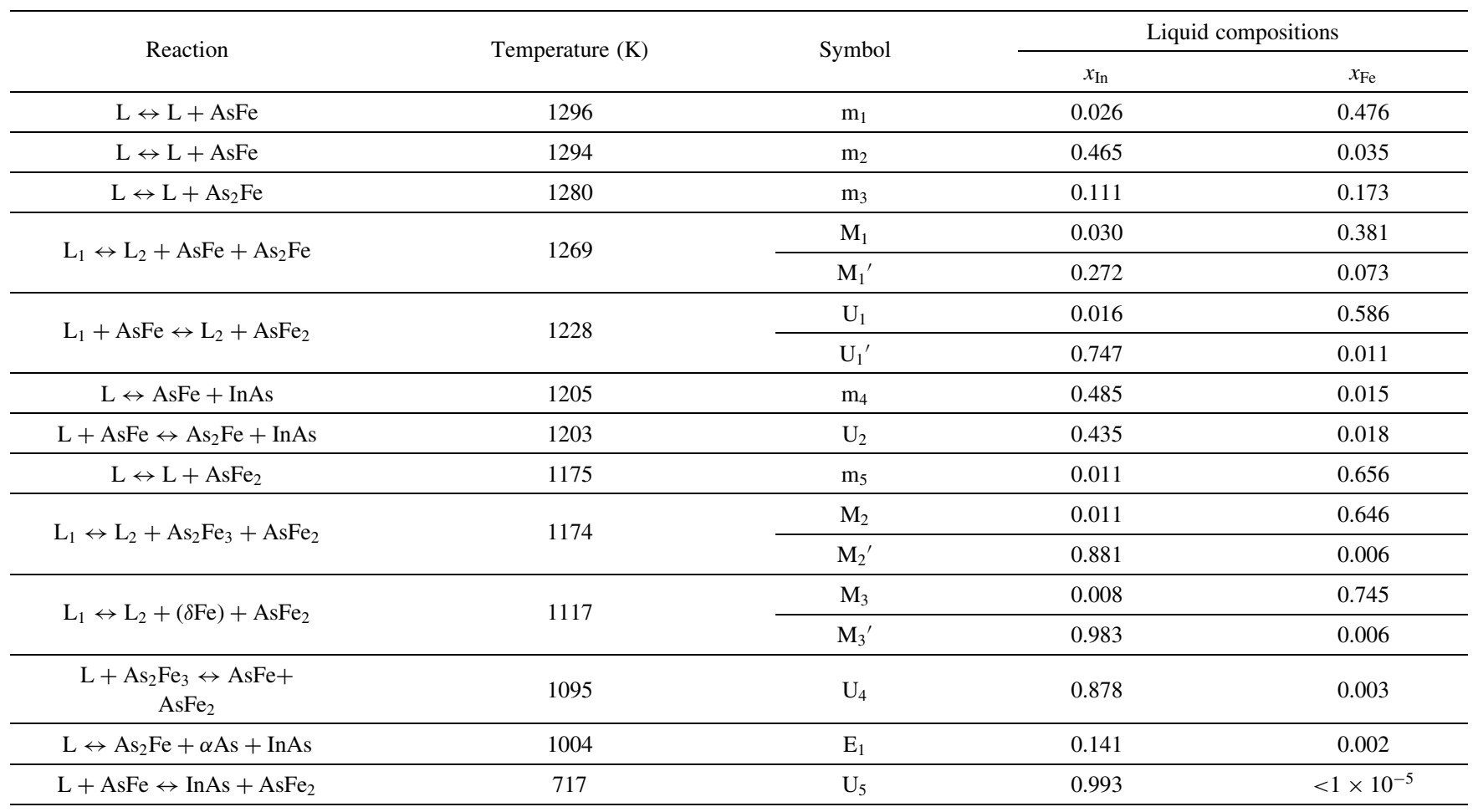

(a)

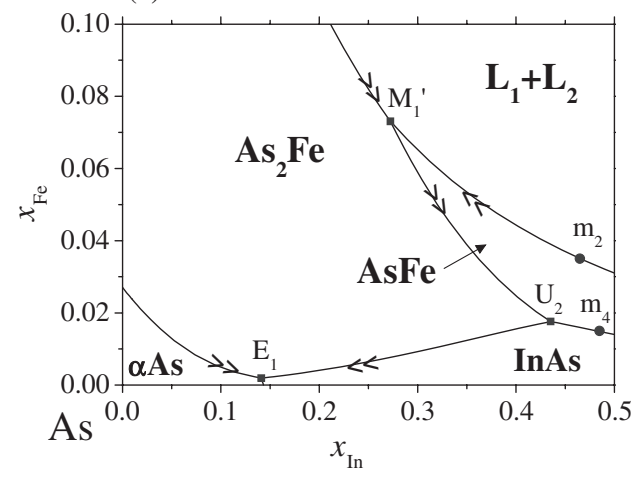

(c)

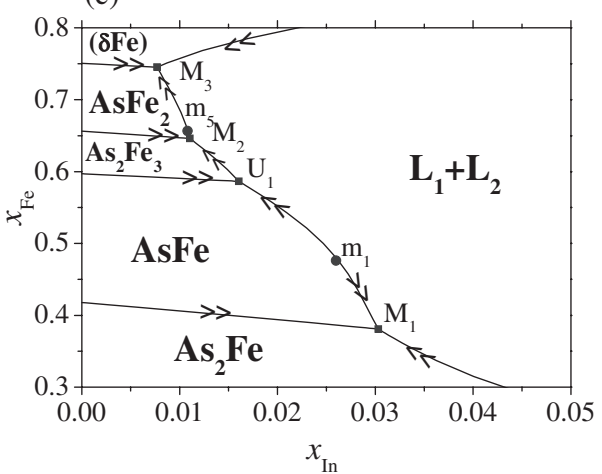

(b)

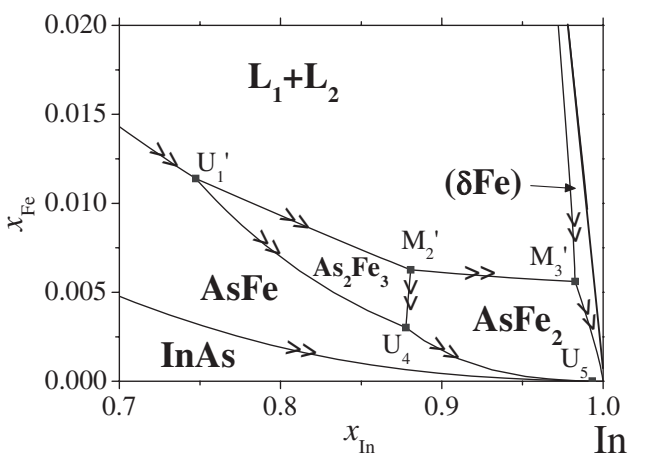

Fig. 3 Enlargement of the monovariant lines in (a) As-rich region, (b) In-rich region and (c) As-Fe binary edges region. The primary crystallizing phase field is indicated in each figure.

the phase equilibria are entirely determined by the thermodynamic state of the binary edge system. The present thermodynamic models for each binary system are considered to be well established based on the reliable experimental data and the first-principles total energy calculations of the formation energies of the compounds. Hence, it is considered that the present result for liquidus surface and invariant reactions should be tentative but close to the reality. 


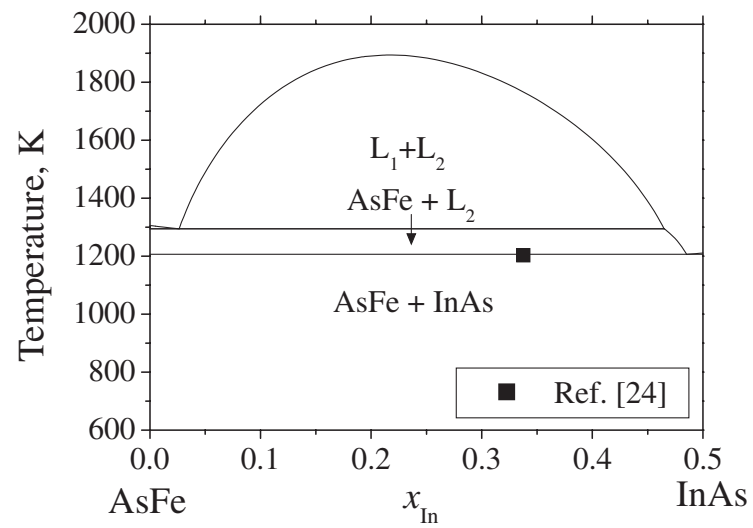

Fig. 4 Vertical section at $x_{\mathrm{As}}=0.5$ between $\mathrm{AsFe}$ and InAs compounds.

As already mentioned in the introduction, the optimization of the fabrication process parameters for spin injection device has been currently attempted by a trial and error. It is generally considered that growth process of $\mathrm{Fe}$ on semiconductor in relatively high temperature range $(420-450 \mathrm{~K})$ does not suffer from the formation of defects in the Fe film. However, the recent work showed that the epitaxial growth of Fe films on the InAs substrate at $450 \mathrm{~K}$ involves the interface reaction, resulting in the formation of a compound at the interface. ${ }^{7)}$ On the other hand, the fabrication process at $296 \mathrm{~K}$ leads to a clear interface, i.e., the interface without the formation of compound. ${ }^{7}$ ) The critical temperature at which the reaction occurs at the $\mathrm{Fe} / \mathrm{InAs}$ interface has not been clarified. The calculated isothermal section at $300 \mathrm{~K}$ is shown in Fig. 5(a). It is noted that at this temperature, the energy of the formation of the compounds plays a dominant role in determining the phase equilibria. The accuracy for InAs, AsFe binary compounds are well supported by the experimental data and the first-principles calculations. ${ }^{14,15)}$ At this temperature, the InAs compound is in equilibrium with the $\mathrm{As}_{2} \mathrm{Fe}$, AsFe and $\mathrm{AsFe}_{2}$, while $(\alpha \mathrm{Fe})$ is not stable in contact with the InAs, which is consistent with the one obtained from the Miedema's estimation of the formation energy of compound. ${ }^{12)}$ Though the identification of the types of the compounds formed at the $\mathrm{Fe} / \mathrm{InAs}$ interface requires the diffusion path between $\mathrm{Fe} / \mathrm{InAs}$ diffusion couples to be investigated in detail, the reaction is expected not to proceed substantially at this low temperature.

The isothermal section at $450 \mathrm{~K}$ is shown in Fig. 5(b). It is noticed that the $\mathrm{Fe} / \mathrm{InAs}$ contact is not directly in equilibrium and its hybrid structure involves a reaction at this temperature. It is important to note that the liquid phase exists in the $\mathrm{AsFe}+\mathrm{InAs}+\mathrm{L}_{2}, \mathrm{AsFe}_{2}+\mathrm{InAs}+\mathrm{L}_{2}$ three phase regions, $(\alpha \mathrm{Fe})+\mathrm{L}_{2}$ two phase region at $450 \mathrm{~K}$. As pointed out by Beyers et al. ${ }^{9)}$ if the liquid phase exists during the growth process of thin film layer on the semiconductor, melting and the re-solidification of the metallization layer occur at the interface. The isothermal section shown in Fig. 5(b) indicates that the liquid phase in the fabrication process at $450 \mathrm{~K}$ may lead to the formation of $\mathrm{AsFe}_{2}$ compound. The present calculation demonstrated that the liquid phase appear at $429.8 \mathrm{~K}$ through a degenerated reaction in the As-In binary edge system. Hence, the fabrication at the temperature lower than $429.8 \mathrm{~K}$ can prevent the reaction
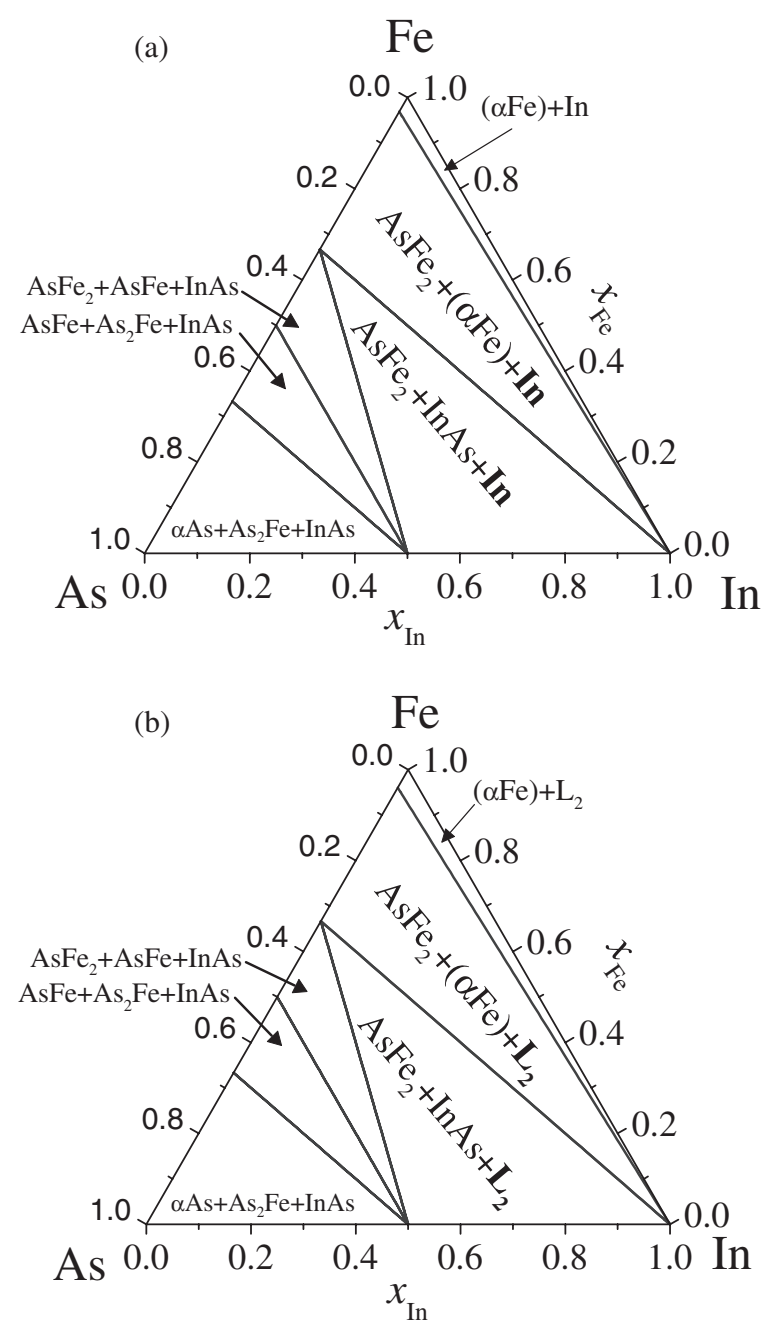

Fig. 5 Calculated isothermal sections at (a) $\mathrm{T}=300 \mathrm{~K}$ and (b) $\mathrm{T}=450 \mathrm{~K}$.

associated with the liquid phase. Although we cannot readily conclude that the reaction at the interface observed at $450 \mathrm{~K}^{7}$ ) is associated with the existence of the liquid phase, the present thermodynamic calculations suggest the growth temperature lower than $429.8 \mathrm{~K}$.

\section{Conclusion}

In this study, we performed the thermodynamic modeling of the As-Fe-In system based on CALPHAD approach. First we presented the thermodynamic modeling of the Fe-In binary edge system. Then, by utilizing the models for As$\mathrm{In}^{15)}$ and $\mathrm{As}-\mathrm{Fe}^{14)}$ systems, the liquidus surface and the invariant reactions were calculated. The special attention was directed to the isothermal sections at $300 \mathrm{~K}$ and $450 \mathrm{~K}$, which are critically relevant to the fabrication process of $\mathrm{Fe} / \mathrm{InAs}$ hybrid structure. The present calculated results are quite suggestive of the possibility that the liquid phase exists at the interface between Fe film and InAs substrate during the fabrication process at $450 \mathrm{~K}$, which leads to the formation of $\mathrm{AsFe}_{2}$ compound. The fabrication at the temperature lower than $429.8 \mathrm{~K}$ can prevent the reaction associated with the liquid phase. The present thermodynamic calculations can be utilized to optimize the fabrication process parameters for $\mathrm{Fe} / \mathrm{InAs}$ hybrid structure. 


\section{Acknowledgements}

This work is supported by grant-in-aid for Young Scientist (B) 19760209 from Japanese Ministry of Education, Culture, Sports, Science and Technology. Also, the author M.O. acknowledges partial support from the Next Generation Super Computing Project, Nanoscience Program, MEXT, Japan.

\section{REFERENCES}

1) G. A. Prinz: Physics Today 48 (1995) 58-63.

2) G. Schmidt, D. Ferrand, L. W. Molenkamp, A. T. Filip and B. J. van Wees: Phys. Rev. B 62 (2000) R4790-R4793.

3) H. J. Zhu, M. Ramsteiner, H. Kostial, M. Wassermeier, H.-P. Schoenherr and K. H. Ploog: Phys. Rev. Lett. 87 (2001) 016601-1-3.

4) Y. B. Xu, D. J. Freeland, M. Tselepi and J. A. C. Bland: Phys. Rev. B 62 (2000) 1167-1170.

5) H. Ohno, K. Yoh, T. Doi, A. Subagyo, K. Sueoka and K. Mukasa: J. Vac. Sci. Technol. B 19 (2001) 2280-2283.

6) M. Tselepi, Y. B. Xu, D. J. Freeland, T. A. Moore and J. A. C. Bland: J. Mag. Magn. Mater. 226-230 (2001) 1585-1587.

7) K. Yoh, H. Ohno, K. Sueoka and M. E. Ramsteiner: J. Vac. Sci. Technol. B 22 (2004) 1432-1435.

8) K. Ishida, H. Tokunaga, H. Ohtani and T. Nishizawa: J. Cryst. Growth 98 (1989) 140-147.
9) R. Beyers, K. B. Kim and R. Sinclair: J. Appl. Phys. 61 (1987) 21952202.

10) H. Cordes and R. Schmid-Fetzer: J. Mater. Sci. Mater. Electronics 6 (1995) 118-126.

11) J. Klingbeil and R. Schmid-Fetzer: CALPHAD 18 (1994) 429-440.

12) J. Klingbeil and R. Schmid-Fetzer: CALPHAD 13 (1989) 367-388.

13) L. Kaufmann and H. Bernstein: Computer Calculation of Phase Daigrams with Special Reference to Refractory Materials, (Academic Press, New York, 1970).

14) M. Ohno and K. Yoh: J. Cryst. Growth 310 (2008) 2751-2759.

15) I. Ansara, C. Chatilon, H. L. Lukas, T. Nishizawa, H. Ohtani, K. Ishida, M. Hillert, B. Sundman, B. B. Argent, A. Watson, T. G. Chart and T. Anderson: CALPHAD 18 (1994) 177-222.

16) H. Okamoto: Phase diagram of binary Iron Alloys ed. by H. Okamoto, (ASM International 1993) 182-184.

17) H. H. Stadelmaier and M. L. Fiedler: Z. Metallkd. 58 (1967) 633-634.

18) C. Dasarathy: Z. Metallkd. 58 (1967) 279-280.

19) C. Dasarathy: Trans. AIME 245 (1969) 1838-1839.

20) A. S. Malyugin and A. D. Pogorely: Izv. V.U.Z. Tsvetn. Metall. 2 (1970) 107-110.

21) A. Dinsdale: CALPHAD 15 (1991) 317-425.

22) M. Hillert and M. Jarl: CALPHAD 2 (1978) 227-238.

23) R. Schmid-Fetzer: Ternary Alloys; A Comprehensive compendium of evaluated constitutional data and phase diagrams ed. by. G. Petzow, G. Effenberg and F. Aldinger, Vol. 10 (1994) 219-221.

24) A. Müller and M. Wilhelm: J. Phys. Chem. Solids 26 (1965) 2029_2035. 